\title{
Percepção dos enfermeiros docentes frente ao processo de morte e morrer
}

\author{
Teresa Cristina Gioia Schimidt, D.Sc.*, Juliana Aparecida Ribeiro Parreira**
}

*Enfermeira, Docente Colaboradora no Departamento Médico Cirúrgico da Escola de Enfermagem da USP, Docente no Departamento de Saúde da Universidade Nove de Julho, Enfermeira da Secretaria de Estado da Saúde de São Paulo, Integrante do Grupo de Pesquisa e Estudo sobre Comunicação em Enfermagem do CNPq. São Paulo/SP **Enfermeira, Mestranda em Ciências da Saúde pelo Instituto de Assistência Médica ao Servidor Público Estadual, Docente no Departamento de Saúde da Universidade Nove de Julho São Paulo/SP

\section{Resumo}

Estudo descritivo qualitativo transversal com objetivo de identificar dificuldades em lidar com o processo de morte/ morrer e sentimentos/pensamentos frente à problemática. Desenvolvido em 2012 por meio de entrevista com 24 docentes enfermeiros da Universidade Nove de Julho/SP. Os resultados diante das dificuldades em cuidar de paciente em processo de morte e morrer foram categorizados: âmbito emocional, âmbito comunicacional, âmbito ético-filosófico e âmbito educacional. Os sentimentos foram: impotência, frustração e culpa; tristeza, comoção, lamento e pesar; aceitação, alívio e empatia; indignação e desespero. Quanto à percepção que possuem quando cuidam, seis categorias emergiram: condição evitável; influência espiritual; aspecto bioético; exposição das relações familiares; processo natural e expressão de sentimentos. Concluiu-se que parte dos profissionais apresenta dificuldade em lidar com a morte, sendo apontados os problemas ligados às emoçôes, comunicação, ética e educação. Uma variedade de sentimentos e fragilidades, quando cuidam do paciente nas condiçóes referidas, foi assumida revelando a complexidade do assunto.

Palavras-chave: morte, atitude frente à morte, tanatologia, enfermagem.

\section{Abstract \\ Perception of nurse teachers regarding the death and dying process}

This descriptive, qualitative, cross-sectional study aimed to identify the difficulties in coping with the death/dying process and the feelings/thoughts when faced with the issue. It was developed in the 2012 through interviews with 24 teachers at University Nove de Julho/SP, Brazil. The results regarding the difficulties in caring for a patient in the death and dying process were categorized in context: emotional, communicative, ethical-philosophical and educational. The feelings encountered were: impotency, frustration, and guilt; sadness, shock, regret/grief; acceptance, relief/ empathy; indignation/despair. Regarding the perceptions of the subjects when caring, six categories emerged: preventable condition; spiritual influence; bioethical aspect; exposure of the family relationships; natural process and expression of feelings. It was concluded that the professionals presented difficulty in coping with death, with the problems related to emotions, 
communication, ethics and education being highlighted. A variety of feelings and fragilities, regarding patient care under these conditions, were revealed demonstrating the complexity of the subject.

Key-words: death, attitude to death, thanatology, nursing.

\section{Resumen}

\section{Percepción de los enfermeros docentes frente al proceso de la muerte y de morir}

Estudio descriptivo cualitativo transversal con objetivo de identificar dificultades en lidiar con el proceso de la muertel morir y sentimientos/pensamientos frente a la problemática. Desarrollado en 2012 a través de entrevista con 24 docentes de la Universidad Nove de Julho - SP, Brasil. Los resultados delante de las dificultades en cuidar de paciente en proceso de muerte y morir fueron categorizados: emocional, comunicacional, ético-filosófico y educacional. Los sentimientos fueron: impotencia, frustración/culpa; tristeza, conmoción, lamento/pesar; aceptación, alivio/ empatía; indignación y desesperación. A la percepción que poseen cuando cuidan, seis categorías emergieron: condición evitable; influencia espiritual; aspecto bioético; exposición de las relaciones familiares; proceso natural y expresión de sentimientos. Se concluyó que parte de los profesionales presenta dificultad en lidiar con la muerte, siendo apuntados los problemas relacionados a las emociones, comunicación, ética y educación. Una variedad de sentimientos y fragilidades, cuando cuidan del paciente en las condiciones referidas, fue asumida, revelando la complejidad del asunto.

Palabras-clave: muerte, actitud frente a la muerte, tanatología, enfermería.

\section{Introdução}

A ação do tempo traz inúmeras conquistas e desafios, dentre eles o envelhecimento humano. Este tempo é individual e esgota-se com a finitude objetivada pela morte biológica, a qual faz parte da vida do homem. Mesmo fazendo parte da trajetória, a morte é, ainda, encarada no mundo ocidental como um tabu, embora seja inevitável, permanece como uma condição complexa que merece ser discutida. A morte quando considerada como uma perda, independentemente do ciclo vital do indivíduo, o luto e seu processo de elaboração concedem oportunidades de reconstruir, utilizar recursos e fazer adaptaçôes às mudanças da própria vida, dando ou não novo sentido.

Estudos revelam que o processo de morte gera insegurança, medo, inquietação e ansiedade, fazendo com que o ser humano sofra com a morte do outro, pois nela ele se percebe [1].

Conviver com a morte e seu processo fazem parte da rotina dos profissionais de saúde. Portanto, estes necessitam ir além de suas explicaçóes, compreendendo que esta situação constitui uma fonte possível e estratégica de cuidar efetivo do humano. Apesar de próxima, a morte, muitas vezes, é compreendida como algo distante, evento novo que causa impotência e outras emoçóes que podem interferir no cuidado [2-3].

Algumas vezes, o cuidado é encarado e reduzido pelos profissionais de saúde como sinônimo de cura. Há uma tendência de negligenciar que a finitude faz parte do processo, mesmo reconhecendo que o contato com tais situaçóes traz sofrimento e gera conflito que, quase sempre, não são poupados [4].

O convívio com a dor, perda e morte traz aos profissionais vivências de seus processos internos. A morte do outro remete à consciência da própria morte, e este parece ter sido um dos motivos de dificuldade para atuação dos referidos profissionais ao prestarem assistência aos que necessitam. É interessante citar que a morte ultrapassa um momento dramático, pois pode constituir uma ocasiáo única para atribuir um sentido à vida [3,5].

$\mathrm{Na}$ maioria das vezes, a morte é considerada como um fracasso para os profissionais da saúde. A equipe prepara-se para salvar vidas e quando isso acontece o cuidado é encarado como algo heroico, no qual a situação, de fato, conseguiu ser controlada, mas, quando ocorre a morte, muitas vezes, desencadeia nos profissionais sentimentos de fracasso, impotência, medo, descontrole emocional, desespero, gerando o processo de luto. Surgem, então, mecanismos de defesa que podem ser inconscientes, como os sintomas psicossomáticos, resultando no esgotamento psíquico do profissional [4-5].

Essa dificuldade em lidar com o processo de morte e morrer tem gerado uma série de problemas que atingem, especialmente, os profissionais de saúde, adoecendo-os em decorrência do desgaste emocional. É comum identificar reação, face às 
experiências estressantes acumuladas, ao longo do tempo, de um cuidar desleixado e, até mesmo, indiferente como recurso de enfretamento [6].

A falta de preparo para lidar com a morte, bem como as longas jornadas de trabalho, condiçóes nas unidades de internação, como escassez de funcionários e o acúmulo de atividades colaboram, para que a eficácia do cuidar esteja ameaçada [6].

Constata-se que durante a formação dos profissionais da saúde se deu ênfase, por muito tempo, no ensino de conteúdos programáticos ligados ao conhecimento dos aspectos estritamente técnicos como o diagnóstico e o manejo das doenças, em detrimento a inserção de assuntos que pudessem incentivar uma maior discussão dos aspectos humanísticos, como por exemplo, a percepção e os limites ligados ao processo de morte e morrer [3-6].

Tendo essa vertente como pauta, se colocou algumas questóes para este estudo: Até que ponto os profissionais de enfermagem sentem-se preparados para lidar com a morte? Quais os sentimentos e as dificuldades desses profissionais diante do processo de morte e morrer? Considera-se que estas respostas possam de alguma forma, contribuir na reflexão e na ação ética no cotidiano dos serviços de saúde, proporcionando, assim, um cuidado mais humano e solidário àqueles que vivenciam esse processo.

Este estudo teve o objetivo de apreender o modo como o enfermeiro lida com o processo morte/morrer dos pacientes, procurando identificar as dificuldades e sentimentos frente a esta situaçáo.

\section{Material e métodos}

Estudo descritivo, qualitativo, desenvolvido com os docentes enfermeiros que compunham o quadro de pessoal de uma universidade privada da capital paulista. A amostra constituiu-se de 24 enfermeiros, corresponde a $10 \%$ do total que trabalha na instituição.

O critério de seleção foi aleatório e de conveniência, independentemente de gênero, idade e tempo de docência ou de formação em Enfermagem, desde que aceitasse participar do estudo, mediante autorizaçáo expressa por meio de assinatura do Termo de Consentimento Livre e Esclarecido (TCLE) e que tivesse experiência mínima de um ano no âmbito assistencial.

O instrumento utilizado foi um questionário que agregou perguntas para caracterização pessoal dos participantes e questóes abertas como: "Quais as maiores dificuldades que você têm/teve em cuidar de um paciente em processo de morrer/morte? $\mathrm{O}$ que sente/sentiu sobre a morte do paciente? O que pensa/pensou quando cuida de um paciente que esteja em processo de morte/morrer?".

A coleta de dados ocorreu no $2^{\circ}$ semestre de 2012, após a aprovação do Comitê de Ética em Pesquisa com Seres Humanos (Parecer CEP no. 438.122/2011). Tanto o convite de participação, como a participação em si, estabeleceu-se após a explicação da metodologia do trabalho, posteriormente, a assinatura do TCLE. O preenchimento do questionário foi feito, antes ou após as aulas programadas, na sala dos professores, como uma forma de garantir que as atividades trabalhistas não fossem prejudicadas. Para a preservaçáo do anonimato dos participantes, todos os profissionais receberão questionário em envelope do tipo carta individual não identificado. Não foi estipulado um prazo em minutos para seu preenchimento, solicitou-se apenas que fosse respondido no mesmo período (manhâ, tarde ou noite) e que os mesmos, após, respondidos, fossem sem qualquer tipo de informe em duas pastas (TCLE e Respostas) especialmente criadas e identificadas para esse fim que foram disponibilizadas na sala dos professores durante o período de coleta de dados.

Ressalta-se que não houve riscos, desconfortos e ou inconvenientes aos sujeitos participantes, bem como quem participou não recebeu qualquer tipo de benefícios.

Os dados contidos nos questionários foram devidamente digitados em planilha do Excel versão 2007 que serviu como banco de dados da pesquisa, facilitando tanto a tabulaçáo dos dados como sua própria organizaçáo e análise. $\mathrm{O}$ tratamento dos dados constou de leitura detalhada das respostas, a identificação de similaridades e a construção de categorias temáticas [7].

\section{Resultados e discussão}

Participaram do estudo 24 enfermeiros, sendo 75\% (18) do gênero feminino, com idade média de 50,8 anos e $25 \%$ (6) do gênero masculino, com média de 37 anos de idade. $\mathrm{O}$ número de anos de formação acadêmica entre as enfermeiras foi de 21 , e o dos enfermeiros de 11,8 , sendo a média geral de 16 anos, com intervalo de 7 a 32. A experiência com docência, tanto no ensino técnico, como no superior, foi investigada sendo, a média em anos 
de 6,4 e 8,9 anos, respectivamente. Já o número de anos em experiência assistencial foi de 16,4, para o gênero feminino, 8,5 para o masculino, com média geral de 12,3 . O tempo médio de preenchimento do questionário foi de 18 minutos.

As respostas frente ao questionamento sobre as dificuldades em cuidar de um paciente em processo de morte e morrer deram origem a quatro categorias distintas: âmbito emocional, âmbito comunicacional, âmbito ético-filosófico e âmbito educacional.

A categoria âmbito emocional $(58,4 \%-14)$ englobou as respostas com conteúdos ligados aos sentimentos de impotência, onipotência, culpa, fuga, aceitação frente às condiçôes apresentadas pelo paciente na condição de morte e morrer. Eis algumas descriçóes que o ilustram:

Não tenho dificuldades em lidar com paciente morrendo, pois morrer no hospital é comum, e eu sei separar as coisas, ele é ele e eu? Eu faço o que posso fazer (E5). Manter a postura profissional perante os familiares sem mostrar envolvimento, sem me envolver sentimentalmente. Eu, eu não posso nem chorar, nem ficar triste (E21).

Esse resultado vai ao encontro do descrito pelas autoras [5] que mencionam o quanto os docentes de enfermagem relatam possuir um alto nível de ansiedade e medo de enfrentamento sobre a temática o que interfere na prática assistencial deles.

Outro assunto importante é o tempo de permanência na internação do paciente, pois este contribui para a intensificação do sofrimento de quem cuida, uma vez que o vínculo emocional tende a ser construído e intensificado em cada plantáo.

A categoria, âmbito comunicacional, reuniu $33,4 \%$ (8) das respostas ligadas às dificuldades inerentes ao processo de dar e receber informaçóes de maneira clara, objetiva, mantendo a afetividade na forma de dar a notícia; identificaçáo do momento adequado e ajustado, para que a família possa participar do cuidado prestado e na manutenção adequada do vínculo terapêutico. Alguns exemplos:

Identificar as necessidades e sofrimentos do paciente que tem dificuldade de comunicação verbal e, assim, integrar a família nesse processo (E8). Lidar com a família, principalmente quando o médico não deixa claro o quadro do paciente (E6).
Os profissionais de saúde têm a missão de zelar por uma assistência de qualidade no cuidado de todos os pacientes, independente da situação em que se encontram e devem manter a dignidade dos mesmos.

Os pacientes necessitam de tempo com qualidade da equipe de saúde para que possam expressar suas dúvidas, anseios e preocupaçôes. A escuta qualificada é um dos recursos técnicos que precisa ser utilizado com maior frequência nos serviços hospitalares. Trabalho desenvolvido na Unidade de Tratamento Intensivo evidenciou que há necessidade da fala sem eufemismo, com conhecimento real da situação do paciente, para que possa, de maneira clara e simples, fornecer informaçóes de sua condição, aliviando ansiedade, elucidando dúvidas e, assim, exercendo um papel confortador, de fortaleza e que mantenha a esperança [2].

É oportuno salientar que todo profissional necessita ter como base de seu trabalho as relaçóes humanas, sejam elas com o cliente, com sua família ou com a equipe multidisciplinar. A dimensão afetivo-expressiva, portanto, faz parte da ação terapêutica do cuidado e pode ser explicitada pela relaçáo de confiança, no trato com carinho, no ser gentil, no demonstrar compreensão, conversar, tocar, falar, escutar, olhar, dar força, interessar-se, aconselhar e outros [8].

Considera-se cuidado humano efetivo/afetivo, quando este é balizado pelo diálogo, no qual a escuta é privilegiada e com espaço para perguntas abertas, tal atitude favorece a participação da família [8].

A comunicação é composta por duas partes: a primeira, possui relação com o conteúdo, o fato, a informação que se deseja e tem intenção de transmitir e ele acaba por expressar, em parte, o referencial de cultura dos envolvidos e, a segunda, relaciona-se com o sentido que se dá à emoção da comunicação, evidenciada pela forma de falar, os silêncios concedidos e as expressóes emitidas. Para que esta conversa/ relaçáo comunicacional seja eficaz, exige domínio das circunstâncias (profissional e do paciente) e conscientização de sua intencionalidade [9].

A categoria, âmbito ético-filosófico, reuniu $25 \%$ (6) das respostas ligadas às reflexóes sobre o ter e o ser na vida, daí, emergiram a recordaçáo de princípios éticos, tais como, a veracidade, solidariedade e autonomia e, ainda, questionamento diante do gasto com material e a ocupação de leitos com pacientes terminais. Algumas das respostas que compóem essa categoria foram assim expressas: 
Entender a recusa do paciente em receber o cuidado e fingir que tudo ficará bem e concordar com o que se diz (E7). Não tem mais nada a ser feito e por que está lá? Ele fica ali e gasta material, sem dizer que desgasta todos da equipe (E5).

Os valores que são concedidos aos objetos materiais e às pessoas com as quais convivemos, traduzem o juízo de valor que é produzido pelo modo de viver de cada indivíduo, sendo resultado da vontade voluntária, livre e realizada com conhecimento. As maneiras de lidar e viver a própria vida são frutos dos desejos, das crenças e do que é posto e cobrado pela sociedade. Cada decisão do homem é regada de novas possibilidades e traz direçôes distintas ligadas com o modo de viver e de buscar a felicidade e isso tem congruência com o querer e com o próprio autoconhecimento, bem como a capacidade de escolher e decidir pelo que se deseja [9].

Muitas vezes, o profissional de enfermagem, em detrimento de um cuidado ético, supervaloriza o técnico, revelando dificuldades em compreender as reais necessidades do paciente em processo de morte/morrer, negligenciando sua totalidade, bem como, a integralidade do cuidado.

Estudo desenvolvido com enfermeiras baianas verificou que a relação do profissional de enfermagem com os familiares requer a busca permanente de apoio e confiança, independentemente se o cuidado ocorre no contexto instrumental ou expressivo [2].

A confiança requer reconhecer as diferenças existentes e resgatar, continuamente, a intenção da interação e do cuidado. Ela é estabelecida pela veracidade das informaçóes e pelo respeito ao desejo do que o paciente solicita ou decide. A responsabilidade com a verdade ratifica a condiçáo de ser ético na profissão exigida pelo Código de Ética dos Profissionais de Enfermagem (COFEN). Por mais difícil que seja a situação, é necessário o paciente ter conhecimento da verdade sobre seu estado de saúde para que os princípios de solidariedade e autonomia façam parte da seara do cuidado [10].

A quarta categoria, âmbito educacional, reuniu 20,8\% (5) das respostas ligadas ao despreparo técnico dos profissionais de enfermagem, refletido no desconhecimento do preparo do corpo do paciente pós-morte, a não compreensão das etapas do processo de morrer, gestáo e liderança da equipe e, ainda, a adaptaçáo do cuidado, em conformidade com a etapa que o paciente/família se encontram. Eis algumas respostas que ilustram esta categoria:

Dificuldade em preparar o corpo (E15). Preparar a equipe para atender à família, prestar cuidados e identificar as alteraçóes apresentadas pelo paciente em cada ocasião (E20).

Percebe-se que parte dos profissionais apresenta dificuldades em lidar com a morte e, muitas vezes, náo encontra suporte adequado no ambiente de trabalho, nem tampouco, em sua formação acadêmica.

O processo de formação deve contribuir para o desenvolvimento de competências e habilidades específicas relacionadas ao cuidado ao final da vida, porém, lamentavelmente, muitas vezes, verificam-se ausências de disciplinas que discutam os aspectos cognitivos e afetivos relacionados ao processo de morte e morrer [4].

É de fundamental importância discutir, tanto na graduação como no ambiente de trabalho, questôes que preparem os profissionais para cuidar de pessoas em situação de finitude [5].

Não sabendo identificar os estágios da morte, torna-se mais difícil para o profissional executar o cuidado e, também, orientar os familiares para que se atentem às alteraçóes apresentadas pelo paciente [10].

Verificou-se uma diversidade de sentimentos dos enfermeiros em relaçáo ao processo de mortel morrer e, para facilitar a apresentação, optou-se em agrupá-los, como se segue.

O primeiro agrupamento foi composto de sentimentos como impotência, frustraçáo e culpa $75 \%$ (18). Eis algumas descriçóes que o ilustram:

\footnotetext{
Nós, seres humanos no processo de morte, verificamos que somos bastante impotentes sem saber, muitas vezes, o que fazer, para que não venhamos a perder esse paciente (E2). No início da profissão, tive algumas dificuldades, principalmente, pessoal, de ficar com a sensação de impotência, de ter deixado de fazer tudo o que era possível pelo paciente; hoje, não mais (E6).
}

Os referidos resultados remetem à pesquisa desenvolvida com graduandos de enfermagem na Bahia, em relação ao preparo para o enfrentamento da morte e o morrer, que evidenciou que o assunto 
atormenta tanto quem se encontra no fim de seus dias como aquele que o acompanha, gerando estresse, ansiedade, angústia e culpa [11].

Outro estudo desenvolvido com docentes e discentes de enfermagem apresentou resultados semelhantes, no que se refere à percepção dos sentimentos como frustração e culpa, além deles, na maioria, relatar dificuldades em lidar com tal situação e, tampouco, com seus próprios sentimentos [6].

$\mathrm{O}$ segundo agrupamento apresentou sentimentos de tristeza, comoção, lamento e pesar $62,5 \%$ (15). Seguem alguns exemplos:

No início, tristeza. Hoje, com a experiência de vida, tenho maturidade para lidar com o processo de morte/morrer, lamento, sim, mas, não depende de mim (E4). Depende do tipo de morte. Não sabemos quando ela chega, nem de que jeito vem. A morte inesperada me levava, muitas vezes, a refletir sobre o sentido da vida, e isso sempre me deu tristeza, sabe, quando o paciente estava bem (alta hospitalar) e depois retornava grave e incidia com a morte, era difícil! Tenho pesar pela família que fica, fico comovida (E15).

Diariamente, os profissionais de enfermagem vivenciam situações especiais que desencadeiam envolvimento afetivo com pacientes e família. Estudo realizado com enfermeiras que exerciam suas atividades com pacientes oncológicos, revelou o quanto elas assumiram sofrer, gerando tristeza e sensação de vazio [12].

O fato é que a morte constitui um acontecimento que choca e promove sofrimentos distintos. O profissional, ao cuidar de um paciente que agoniza, tem a induçáo pela consciência da singularidade de cada indivíduo, o que remete à própria finitude e limitação da vida. Em parte, o sofrimento e o pesar provêm da imposição posta pelos modelos biológico, curativo e tecnicista que influenciam o pensamento e as açóes de cuidado [5].

Urge, então, a necessidade da rotura do paradigma biomédico que reduz o humano a um corpo físico. O profissional, quando reconhece os aspectos da integralidade da assistência, aproxima-se da importância da família no contexto, valoriza o preparo psicológico, no sentido de prevenir os conflitos psíquicos, incluindo, aí, o pesar diante do fenômeno da morte [13].
O terceiro agrupamento foi composto pelos sentimentos de aceitação, alívio e empatia 41,7\% (10), conforme apresentado:

Os sentimentos variam muito de acordo com
a situação da morte. Em casos onde a morte
náo era esperada, o sentimento de perda era
muito grande, já nos casos em que o estado
de sofrimento era grande para o paciente,
era mais fácil a aceitação e a perda (E8).
Quando o paciente é mais velho/doente e
que está sofrendo sinto alívio, não fico com
a consciência pesada, não (E5).

Parte dos profissionais de enfermagem aceita a morte de idosos e/ou daqueles portadores de doença terminal, pois, considera que ela, não somente, faz parte de um percurso natural da vida e, também, traz alívio. Entretanto, isto não ocorre, quando o paciente é criança e/ou jovem, visto que há uma associação de que a vida mal começou e não merece morrer, portanto, há maior dificuldade em lidar com eles [13].

$\mathrm{O}$ ato de dar notícia sobre a morte aos familiares do paciente tem sido apresentado como uma das dificuldades dos enfermeiros, pois, acabam colocando-se no lugar da família naquele momento [13].

Solidarizar-se com a família inclui perceber a vulnerabilidade do outro, sua necessidade e a peculiaridade do cuidado. Cuidar com solidariedade correlaciona-se com a empatia, na disponibilidade em agir de forma compreensível, comprometida e responsável que envolve o estar, o ser e o fazer em enfermagem [14].

O quarto, último agrupamento, foi composto pelos sentimentos de indignaçáo e desespero $8,4 \%$ (2), expresso da seguinte forma pelos sujeitos do estudo:

São diferentes sentimentos, pois são pa-
cientes diferentes. Foram 9 anos de pronto
socorro, sinto indignação, quando uma
criança falece por causas extremas (E18).
Trabalho na neonatal e, na maioria das vezes,
fico desesperada, é horrível! (E7).

Algumas mortes, sobretudo aquelas ligadas às causas externas, promovem um sentimento de indignação nos profissionais. Ninguém espera que uma criança ou um jovem morra tragicamente. 
Quando ocorre isto, gera desespero, tanto à família, como aos profissionais [13].

As respostas frente ao questionamento sobre as percepçóes e pensamentos reconhecidos pelos enfermeiros sobre os processos de morte e morrer deram origem a seis categorias distintas: condição evitável; influência espiritual; aspecto bioético; exposição das relações familiares; processo natural e expressão de sentimentos.

A primeira categoria, morte como condição evitável 35,9\% (15), reuniu os discursos que percebem a morte/morrer como uma situação que pode ser prevenida, evitada e prorrogada. Eis duas das falas:

A morte materna desestrutura toda família. Infelizmente, quase sempre, estas mortes poderiam ser evitadas (E1). Percebo que a equipe fica em silêncio, lamenta sim, mas segue o plantáo e não fala sobre isso, pois nada adianta, náo adianta ter tecnologia de ponta e não saber como usar, isso não traz de volta, nem corrige as inúmeras falhas existentes no cotidiano (E5).

Apesar dos esforços governamentais brasileiros para a redução da mortalidade materna, os resultados revelam que eles têm sido insuficientes. No Brasil, dependendo da região do País, as mulheres náo morrem somente pela falta de acesso aos serviços de planejamento familiar, mas, pela reduzida qualidade na assistência prestada durante o ciclo gravídico-puerperal, que inclui o despreparo dos profissionais de saúde [14-15]. Tal situaçáo constitui um dos exemplos que denuncia o quanto as mortes podem ser prevenidas e que, de certa forma, ratifica a categoria em pauta.

Sabe-se que as novas tecnologias diagnósticas e terapêuticas vêm sendo usadas no intuito de melhorar a qualidade assistencial e aumentar a expectativa de vida; entretanto, os eventos adversos relacionados à assistência também concorrem e evidenciam o quanto que os resultados desse trabalho têm coerência com a realidade [16].

A segunda categoria, denominada de influência espiritual 20,5\% (8), trouxe resultados relacionados à importância que a fé assume no sentido de favorecer o entendimento e a aceitaçáo sobre a morte. Seguem os exemplos:

Gostaria que o processo de morte fosse com menos dor física e mais calor humano, e mais alimentação espiritual, pois ela facilita na hora final (E15). Passagem para outro plano. Os pacientes mais espiritualizados são mais generosos, eles aceitam aquela situação com compreensão, oração e fé. É triste, quando o paciente é desesperado, apegado a bens materiais e não tem crença, não tem fé (E16).

Esse aspecto é ratificado pelo estudo que relaciona a espiritualidade com melhor qualidade de vida, mobilizada pela energia e iniciativa extremamente positivas que fortalecem o indivíduo, fazendo com que ele tenha condiçóes mais eficazes de responder ao tratamento. A fé faz o indivíduo acreditar em uma provisão sobrenatural, capaz de intervir favoravelmente em situação concreta de vida e em seu adoecimento, compreendendo melhor a situação que vivencia [17].

A terceira categoria, intitulada como aspecto bioético $15,4 \%$ (6) reuniu a percepção ligada à autonomia do paciente e às açóes de cuidado que mantenham a dignidade do indivíduo que vão além da morte. A seguir, os discursos traduzem:

Penso que, em alguns casos, é o querer do paciente que deva ser valorizado (E11). Penso que a vida está muito relacionada à vida que levamos, temos muito estresse. Que o cuidado da enfermagem não acaba com a morte, o papel do enfermeiro está além das tarefas executoras da prática ele envolve o conforto e as questôes éticas e bioéticas, têm ainda o que se fazer no pós (E20).

Esse resultado vem ao encontro da busca que a Enfermagem deve fazer ao máximo, frente ao favorecimento do conforto do paciente, ajudando-o a vivenciar o processo de morrer com toda dignidade a que tem direito [1].

O profissional de saúde aprende a lidar com a doença, mas, nem sempre, sabe lidar com o doente, com o declínio das condiçôes clínicas e/ou emocionais dos pacientes, e os cuidados voltados à higiene e ao conforto físico ganham uma dimensão mais representativa, visto que a autonomia e a dificuldade em cuidar-se surgem. Tal situação traz uma nova demanda para a enfermagem que terá de criar alternativas para assegurar a dignidade e a manutenção dos papéis sociais frente ao próprio paciente e a sua família. É importante salientar que 
a dignidade deve ser estendida, também, no preparo do corpo após o óbito [18].

A quarta categoria, chamada de exposição das relaçóes familiares $12,8 \%$ (5), agregou as respostas cujos sentimentos e arranjamentos da família foram expostos, e as expectativas da Enfermagem do papel do familiar diante da referida circunstância foram reivindicadas. Os exemplos são:

A separação é algo difícil sempre. O ser humano é extremante egoísta, pois mesmo vivenciando o sofrimento do ente querido, tenta ficar com ele e prolongar ao máximo sua vida (E7). O que se percebe é que, em algumas situaçóes, os familiares estáo do lado o tempo todo, porém, em outros casos, os familiares somente comparecem após muitas ligações, quando a gente faz as cobranças da presença de um familiar. Isto é um exemplo que demonstra descaso por parte da própria família (E24).

A morte não se apresenta de modo idêntico às pessoas, variando, conforme os anos e o ciclo de vida, sendo dependente da cultura e das experiências pessoais e familiares. A família é a célula social, cuja formação individual deu início e constitui uma referência importante em toda a vida, inclusive, no final dela. Por conta disso, é comum a reivindicação da presença de seus membros em situaçóes positivas que trazem alegria e nas difíceis, quando o sofrimento parece requerer ser compartilhado [19].

A condição de estar vivenciando o processo de morrer é, sem dúvida, um momento de crise para os familiares, que pode resultar em angústias, dores, lamentos, aproximaçóes, afastamentos, dúvidas e conflitos.

Cabe à Enfermagem compreender esse cenário e agir de maneira racional, técnica e afetiva, ajudando à família no enfrentamento do referido processo, encorajando atitudes positivas e, também, construindo uma relaçáo de confiança e zelo e não, simplesmente, de cobrança ou julgamento.

$\mathrm{Na}$ quinta categoria, a morte foi relacionada ao processo natural 10,3\% (4), agregou as respostas que a percebem como uma etapa da vida. Alguns exemplos que ilustram:

Entendo a morte como uma etapa da vida, um processo natural (E1). Sabia que a morte é apenas uma transição (E21).
Embora a morte seja um evento construído na perspectiva do ciclo biológico e fazer parte integral da existência humana, é um tema evitado, até mesmo, negado na sociedade ocidental, trazendo um desafio ao ser humano.

O processo de morrer e a morte sáo experiências humanas universais compreendidas pela dimensão biológica que ultrapassa e assume outras dimensóes construídas ao longo do tempo e influenciadas pelas crenças, concepçóes e rituais que cercam a temática [4].

Estudo realizado com estudantes de enfermagem registrou que a menção da morte, como uma fase que faz parte da vida, também, foi encontrada. Os alunos mencionaram que "todos um dia iräo morrer", portanto, a morte foi encarada como um processo natural [20].

E na sexta categoria, foram abordadas a empatia e a negação $5,1 \%$ (2), que reuniu as falas que mencionaram o sofrimento inicial e a adaptação posterior, como recursos utilizados para superar o cuidar do paciente em situaçáo de morte ou morrer. Seguem os exemplos:

No início da profissão, você sofre junto com o familiar e fica, às vezes, até sem dormir, mas depois de algum tempo e de tantas vezes vivenciando a mesma situação nós acabamos por ficar "frios", e isso acaba ficando uma coisa rotineira e aprendemos a lidar de uma forma mais tranquila (E6). Sofrimento que a pessoa passou, pensando como será a minha morte (E19).

A empatia, expressa pelo afeto, faz parte da dimensão psíquica. Ela concede oportunidades às pessoas de se sentirem melhores, pois, acaba por favorecer uma vivência humana mais harmoniosa. A reação afetiva de um indivíduo utiliza-se de dois mecanismos distintos: sintonização e irradiação. A primeira refere-se à capacidade da pessoa se influenciar pelo contexto, isso faz com que ela se entristeça, chore, mude seu hábito diante das ocorrências dolorosas, por exemplo. A segunda é caracterizada pelo poder que se tem em disseminar aos outros o estado de afetividade, o que provoca estímulo e motivação [8].

Pesquisa realizada com enfermeiros que correlacionou os tipos de afetos com a satisfação de vida, concluiu que, quando estes expressam afetos positivos em suas relaçóes, sentem-se melhores e 
demonstrando prazer em viver, fato significativo para sua qualidade de vida; entretanto, os afetos negativos acabam por influenciar os níveis de ansiedade e estresse e distanciando o profissional do trabalho, provocando afastamento do paciente e da família [15].

Do ponto de vista psicológico, a atitude de negação perante a morte é bastante compreensível, quando se considera que, para o inconsciente, é inadmissível imaginar um fim real da vida terrena. Portanto, é comum fantasiar, defensivamente, sobre sua própria morte, daí, ser imprescindível aos profissionais de saúde entenderem os mecanismos de reação e defesa e, assim, maximizar a compreensão dos sentimentos expressos, direta ou indiretamente, pelos pacientes [4].

Portanto, pode-se salientar que, ao lidar com situaçóes difíceis e dolorosas da vida, como é o caso da morte de um paciente que se cuida, com a intenção de proteger-se, parte dos profissionais acaba por negá-la e agir ou náo com empatia frente aos familiares e, até mesmo, ao próprio paciente.

\section{Conclusão}

Nesta pesquisa, percebeu-se que a compreensão, a percepçáo e a representaçáo da morte e dos sentimentos envolvidos variam de acordo com a individualidade e o preparo profissional.

Muitas são as dificuldades apontadas pelos enfermeiros em lidar com o processo de mortel morrer, as quais variaram, desde o sofrimento causado pelo processo de morte, como também, aquelas ligadas ao processo de dar e receber informaçóes de modo claro, objetivo, mantendo a afetividade na forma de dar a notícia, as reflexóes sobre o ter e o ser na vida e o despreparo da equipe em enfrentar esta situação.

Muitos enfermeiros preferem evitar a morte, por sentirem-se impotentes e frustrados e, até mesmo, culpados perante a mesma, chegando, inclusive, a utilizar recursos que disfarçam e possam, de certa forma, revelar que tudo está bem. Outros enfermeiros relataram sentirem-se tristes, comovidos, com pesar e, outros, ainda, indignados, aliviados, desesperados ou mesmo empáticos, que tentam avaliar as condiçôes e o contexto da ocorrência e da família e procuram dar apoio.

Parte dos profissionais mostra-se imparcial perante este processo, pois, considera a morte como inevitável, como um processo natural. Para alguns, a morte pode ser considerada a interrupção de um sonho, de injustiça, se pensarmos na criança, pois, esta ainda não teve oportunidade de viver. Questionamentos internos e espirituais, bem como éticos e bioéticos e a repercussão e sentimentos provocados nos familiares frente à vivência da finitude, também, foram aspectos citados.

Assim sendo, foi possível identificar o quanto é complexa a percepção dos docentes enfermeiros sobre o assunto, revelando o quanto, ainda, eles se encontram despreparados para enfrentar às situaçóes de finitude, mesmo sabendo que ela seja inevitável, natural e que traz demandas técnicas, éticas, espirituais e emocionais, tanto ao próprio profissional como à família, contribuindo para a ratificação de que o assunto permanece relevante e deve ser estudado e discutido.

Este estudo avança no conhecimento da área de enfermagem uma vez que expóe a percepção e a compreensão das dificuldades inerentes ao cuidar do paciente na situaçáo de morte/morrer, uma condição comum e cotidiana da prática. Aspecto esse defendido e alicerçado no Código de Ética dos Profissionais de Enfermagem e ratificado pela aplicação dos princípios como: solidariedade, integralidade, singularidade e dignidade.

\section{Referências}

1. Prochet TC. Compartilhando os sentimentos e os pensamentos sobre a morte e o processo de morrer. Enferm Brasil 2009;8(3):131-8.

2. Silva RS, Campos ERA, Pereira A. Caring for the patient in the process of dying at the Intensive Care Unit. Rev Esc Enferm USP 2011;45(3):738-44.

3. Pereira LA, Thofehrn MB, Amestoy SC. A vivência de enfermeiras na iminência da própria morte. Rev Gaúcha Enferm 2008;29(4):536-42.

4. Bertachini L, Pessini L. Encanto e responsabilidade no cuidado da vida: lidando com desafios éticos em situaçôes críticas e de final de vida. São Paulo: Paulinas: Centro Universitário São Camilo; 2011.

5. Pinho LMO, Barbosa MA. The professor-student relationship in coping with dying. Rev Esc Enferm USP 2010;44(1):107-12.

6. Santos JL; Bueno SMV. Death education for nursing professors and students: a document review of the scientific literature. Rev Esc Enferm USP 2011;45(1):272-6.

7. Minayo MCS. O desafio do conhecimento: pesquisa qualitativa em Saúde. 9a ed. São Paulo: Hucitec; 2006.

8. Prochet TC, Silva MJP, Ferreira DM, Evangelista VC. Affection in elderly care from the nurses' perspective. Rev Esc Enferm USP 2012;46(1):96-102.

9. Silva MJP. Comunicação tem remédio: a comunicação nas relações interpessoais em saúde. São Paulo: Loyola; 2008. 
10. Fernandes MFP, Freitas GF. Fundamentos da ética. In: Oguisso T, Zoboli E. Ética e bioética: desafios para a enfermagem e à saúde. São Paulo: Manole; 2006. p. 27-44.

11. Oliveira SG, Quintana AM, Bertolino KCO. Reflexóes acerca da morte: um desafio para a enfermagem. Rev Bras Enferm 2010;63(6):1077-80.

12. Sousa DM, Soares EO, Costa KMS, Pacífico ALC, Parente ACM. A vivência da enfermeira no processo de morte e morrer dos pacientes oncológicos. Texto Contexto Enferm 2009;18(1):41-7.

13. Medeiros YKF, Bonfada D. Refletindo sobre finitude: um enfoque na assistência de enfermagem frente à terminalidade. Rev Rene 2012;13(4):845-52.

14. Santos FS. Perspectivas histórico-culturais da morte. In: Dora I, Santos FS. A arte de morrer: visóes plurais. Bragança Paulista: Comenius; 2007. p.13-25.

15. Waldow VR, Fensterseifer, LM. Saberes da Enfermagem: a solidariedade como uma categoria essencial do cuidado. Esc Anna Nery 2011;15(3):629-32.
16. Barbastefano PS, Vargens OMC. Prevenção da mortalidade materna: desafio para o enfermeiro. Rev Bras Enferm 2009;62(2):278-82.

17. Bousso RS, Poles K, Serafim TS, Miranda MG. Religious beliefs, illness and death: family's perspectives in illness experience. Rev Esc Enferm USP 2011;45(2):397-403.

18. Murakami R, Campos CJG. Religiáo e saúde mental: desafio de integrar a religiosidade ao cuidado com o paciente. Rev Bras Enferm 2012;65(2):361-7.

19. Pereira I, Sera CTN, Caromano FA. Higiene e Conforto. In: CREMESP. Cuidado Paliativo. Sáo Paulo: Conselho Regional de Medicina do Estado de São Paulo; 2008. p. 195-218.

20. Vargas D. Death and dying: feelings and behaviors of nursing students. Acta Paul Enferm 2010; 23(3):40410 . 